\title{
COLD TURKEY
}

\section{Highly popular cold remedies could be banned from sale because of their link to a dangerous drug epidemic that has yet to surface in the UK. Rebecca Coombes asks whether} the authorities are over-reacting

UK drug regulators are favouring making products containing the nasal decongestants pseudoephedrine and ephedrine available on prescription only to try to limit their use in the illicit manufacture of the class A drug methylamphetamine, also known as methamphetamine or crystal meth.

A consultation by the Medicines and Healthcare Products Regulatory Agency could result in the UK having the toughest restrictions on pseudoephedrine in the world as early as this Christmas. Critics, including general practitioner representatives and an eminent pharmacologist, have been swift to liken the move to taking a sledgehammer to crack a nut. They say the drug regulators have been taken in by media hype and overcautiousness among the police.

Although potentially very harmful, methylamphetamine is much less widely used in the UK than in countries such as the United States, Australia, and the Czech Republic, where it is a big problem. In 2004, nearly 12 million people in the US had tried methylamphetamine. Recent estimates suggest that in Australia more people are dependent on methylamphetamine than on heroin. But none of these countries has taken such a hard line on pseudoephedrine. Instead, pack size has been reduced, sales limited to one pack, and names of customers recorded.
The proposal to remove pseudoephedrine from retail sale has also split the medical fraternity-the BMA is in the prescription-only camp, but the Royal College of General Practitioners fears this puts up needless obstacles for patients otherwise happy to self treat colds and coughs and will increase general practitioners' workload.

Industry bodies, such as the Proprietary Association of Great Britain, are unsurprisingly angry that popular consumer products with a 40 year safety record face being withdrawn from counter sale. There are 103 licensed products containing pseudoephedrine and 32 containing ephedrine on the UK marketmost are available over the counter. Over 10 million packs of medicines containing these drugs are sold each year. The association argues that policy should be grounded in UK experience, rather than a fear of what might happen based on international events.

\section{Assessing the threat}

But the argument goes that if methylamphetamine takes hold in the UK the consequences would be serious. International experience shows that once a small number of illicit domestic laboratories become established, abuse of crystal meth rises sharply, leading to an increase in amphetamine related

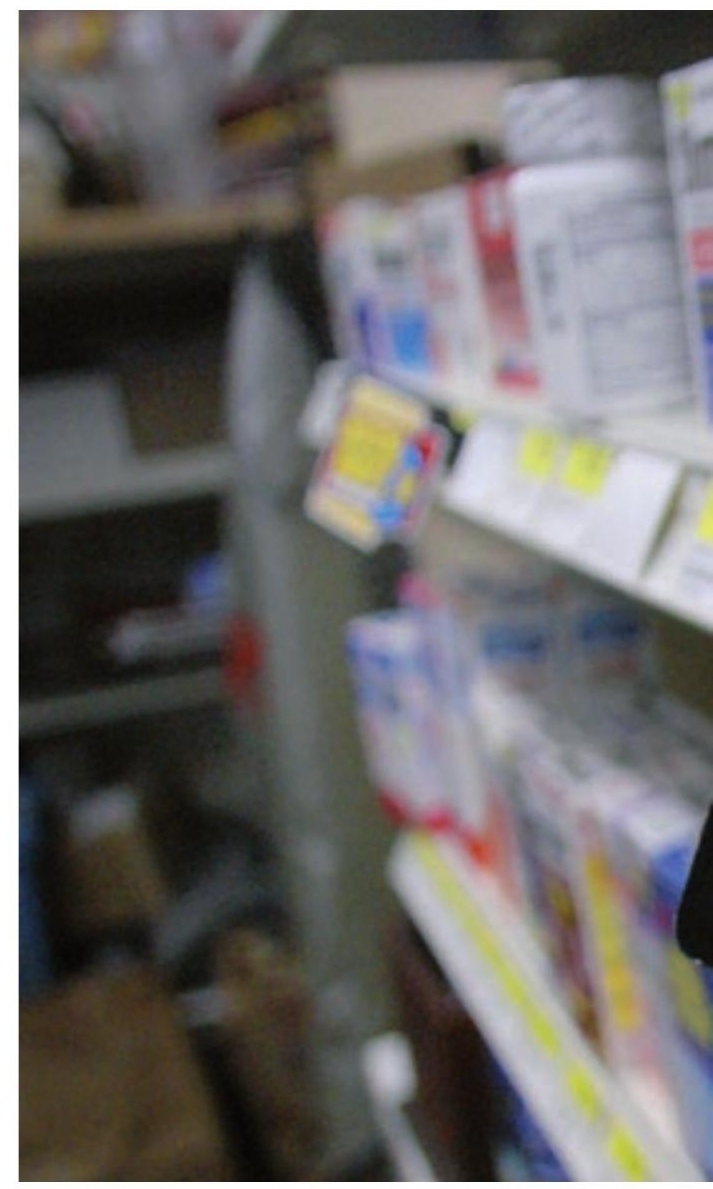

psychoses and, as seen in the US, widespread problems of violence.

In Australia, for example, where half a million people report using the drug, indicators of harm such as psychosis, emergency department presentations, and crystal meth related crime have risen considerably. Between 1999-2000 and 2003-4 amphetamine related psychosis increased by $59 \%$. A study in the Medical Journal of Australia this year found that amphetamine related presentations at emergency departments account for $1 \%$ of all admissions.

UK authorities have plenty of unsettling reports from overseas to show how crystal meth can take a grip on communities. Methylamphetamine is a highly addictive, potent stimulant that affects the central nervous system. When smoked in its crystalline form it can produce effects similar to crack cocaine but lasting considerably longer, up to 12 hours. Methylamphetamine is easy to make from over the counter products containing pseudoephedrine-you don't need any sophisticated equipment, just a kitchen. And step by step instructions on converting pharmacy products into methylamphetamine are readily available on the internet.

But is the UK really on the brink of a 


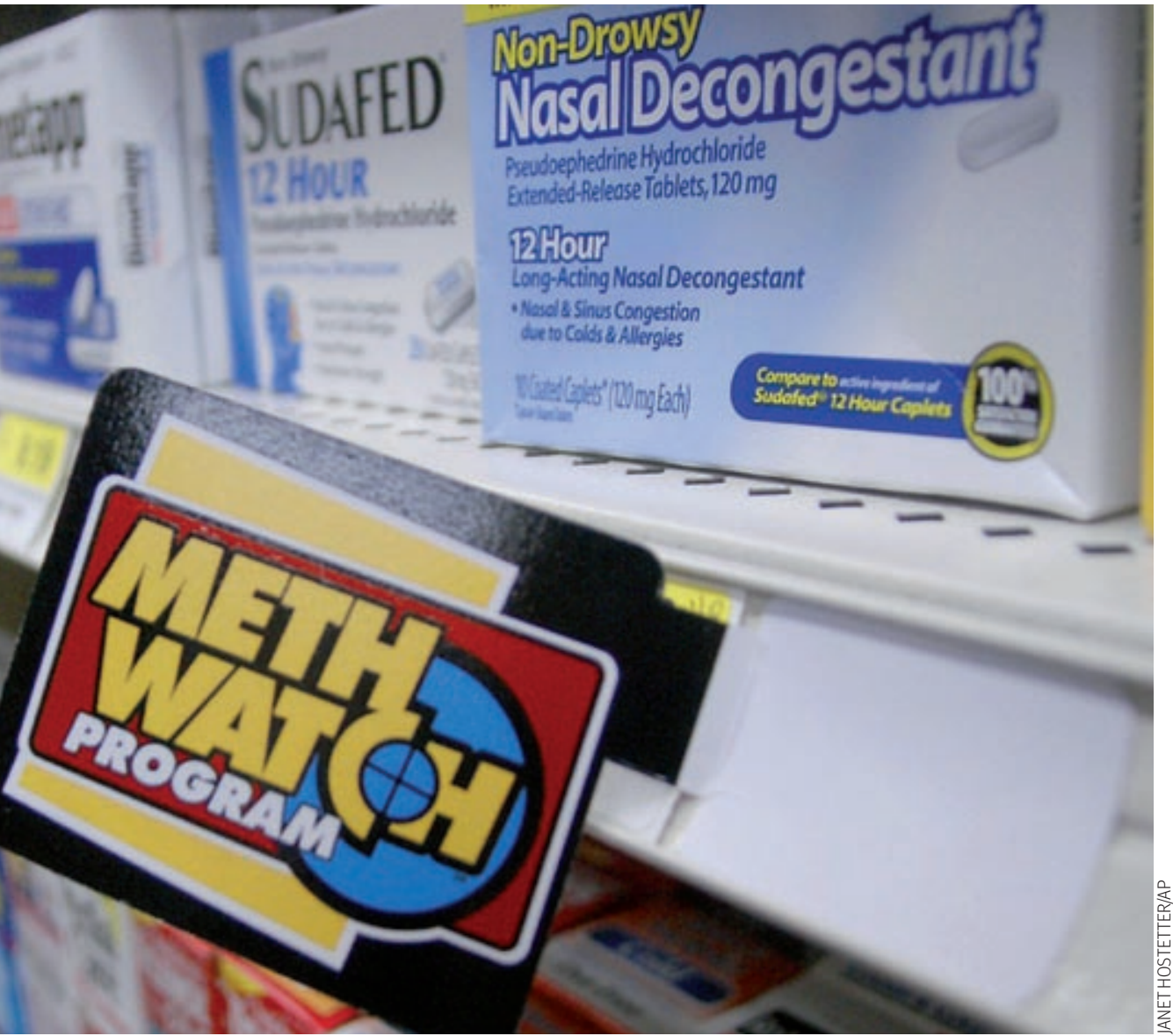

crystal meth epidemic? In April, health minister Caroline Flint told the House of Commons that police had found multiple packs of flu remedies containing pseudoephedrine in raids on drug factories. "They have also identified that, in part, these packs were obtained from numerous pharmacies to obtain adequate quantities for manufacturing," she said.

Although admitting that incidence of illicit activity was low, Ms Flint had been advised that conditions were in place for the drug to take off in the UK. This may well be true. International evidence shows how quickly illicit methamphetamine production and use can increase. For example, the number of illegal laboratories discovered in the US grew from around 300 in 1995 to over 18000 in 2004 .

A 2005 report on methylamphetamine by the Advisory Council on the Misuse of Drugs concluded that use of the drug in the UK was "very limited." Data on its use are scarce because the British Crime Survey, the most comprehensive source of illicit drug taking in the UK, does not differentiate between methamphetamine and ecstasy.

Newly available data from the Association of Chief Police Officers sets out "key threats" to the UK: "There have been several laboratories discovered in England and Wales, the largest . . . was capable of producing a kilo of methamphetamine per cycle," according to its analysis. But only in one case-on the Isle of Wight, where a small scale laboratory was uncovered and the ringleader jailed for 10 years-was there clear evidence of use of pharmacy products.

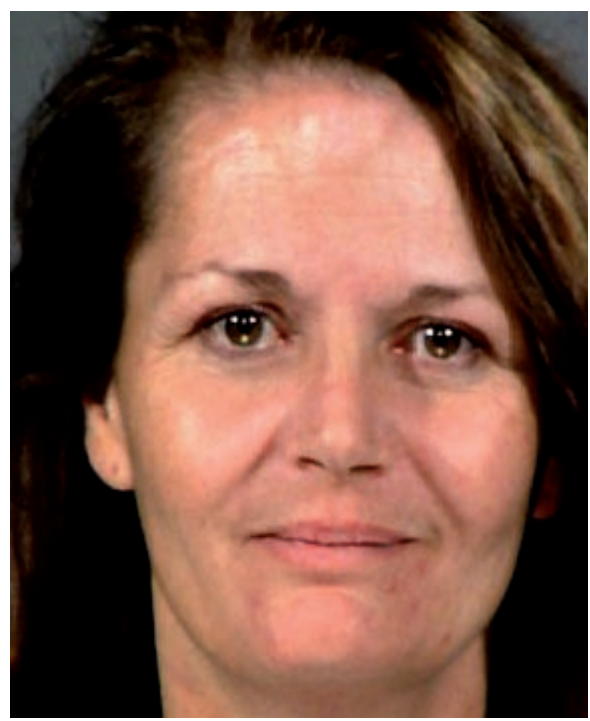

Before and after photographs of a woman following two and a half years of taking crystal meth sory Council on Misuse of Drugs."
Politicians and police in Minnesota introduced "Meth Watch" placards into pharmacies to try to keep tabs on ingredients that go into the drug

\section{An appropriate response}

The limited hard data available on the extent of use of crystal meth do not explain why the UK is proposing such a crackdown on pseudoephedrine cold products. In Australia, for example, where problems far outweigh those in the UK, Alex Wodak, director of the alcohol and drug service at St Vincent's Hospital, Sydney, says that government is unlikely to take a tougher stance. "Australian politicians toyed recently with banning all ephedrine and pseudoephedrine products. There was an outcry and nothing more was heard," he says.

Les Iversen, a member of the Home Office Advisory Council on the Misuse of Drugs, the body which recommends the classification of drugs, and professor of pharmacology at the University of Oxford, is mystified by the UK position. "I deplore the suggestion that pseudoephedrine use be restricted. This is one of the most effective (Cochrane review positive) cold treatments available over the counter. Its illegal use for methamphetamine production is small and could be controlled (as in the USA) by pharmacists issuing only a single box of tablets at a time and taking names of customers. The illegal production of methamphetamine relies more on large scale factories than on home based labs. The MHRA has acted precipitately without consulting, for example, the Home Office Advi-

The chair of the Royal College of General Practitioners, Mayur Lakhani, said

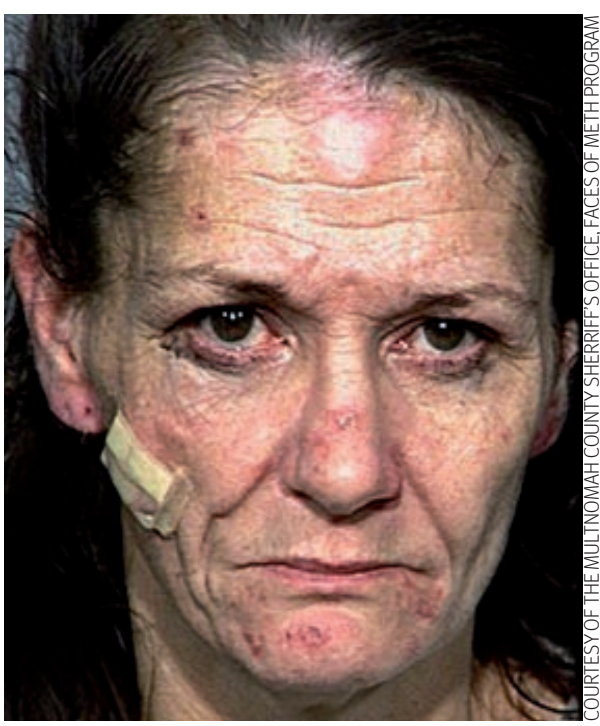




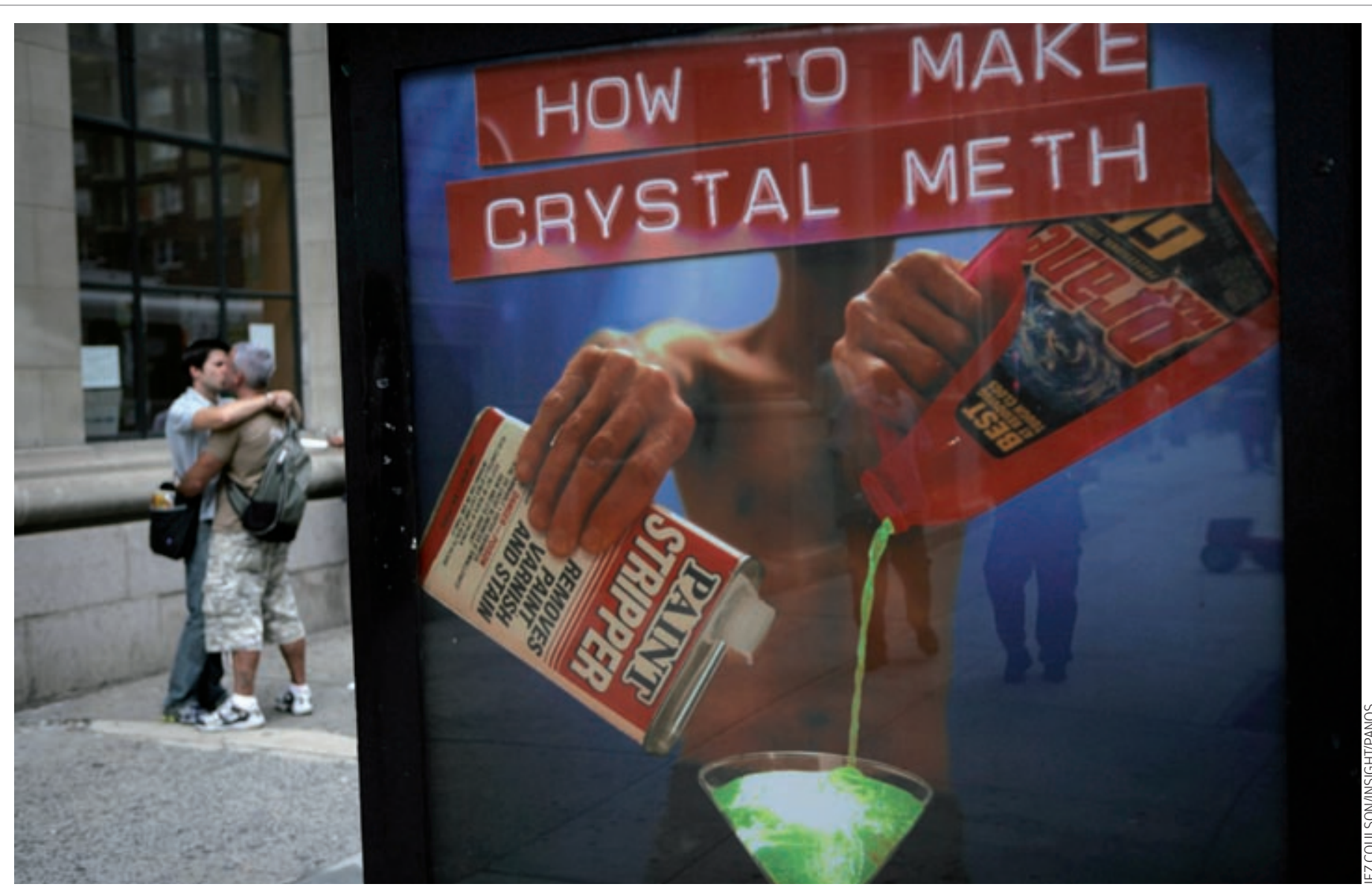

Crystal meth has been blamed for a rise in HIV among New York's gay community

more hard facts were needed before the UK should take the radical step of banning pseudoephedrine from chemists. "Our view is that any response has to be proportionate. It is too easy to suggest making things prescription only. The impact on GP workload would also need to be examined-most GPs do not normally prescribe these drugs. This goes against the move to self care and patient empowerment. The solution must lie with pharmacists."

The Proprietary Associ-

\section{If just a third of people who currently self medicate were to go to the GP, each GP would have an extra 389 visits a year and it would cost the NHS $£ 350 \mathrm{~m}$}

However, the BMA says that making the products prescription only would not deprive consumers of over the counter remedies for coughs and colds, pointing to "safer" alternative drugs such as phenylephrine. A BMA spokesman said: "Any change in the status of these drugs will need to involve a publicity campaign that encourages patients to discuss the alternatives with their pharmacy."

The move to control pseudoephedrine remedies has garnered lots ation of Great Britain claims that 29 million people who have a cold treat it themselves and 12 million adults with blocked sinuses self treat. If popular remedies such as hot lemon preparations are reclassified as prescription only, general practitioners would see a sharp increase in patients with cold and flu. "If just a third of people who currently self medicate were to go to the GP, each GP would have an additional 389 patient visits a year and it would cost the NHS £350m," according to the association. of headlines in the UK, such as "Lemsip turned into a club drug" (Sunday Times, 25 March) and "The Cold War" (Mirror, 26 March 2007). Newspapers have been taking an interest in crystal meth since early 2006 , just before it was reclassified from class $B$ to class A. But even then, a BMJeditorial questioned whether the Home Office advisory council had succumbed to a flurry of media reports about the drug's harms. "Could this be seen as a knee jerk response to a media storm?" questioned Michael Glossop. How proportionate this latest assault will be remains to be seen.

Rebecca Coombes is a journalist, London

rcoombes@bmjgroup.com

Competing interests: None declared.

See editorial, p 1176

1 Medicines and Health Products Regulatory Agency. Public consultation (MLX 337): Proposals to restrict the availability of medicines containing pseudoephedrine and ephedrine. www.mhra.gov.uk/home/

idcplg? IdcService=SS GET PAGE\&useSecondary=tru e\&ssDocName $=$ CON2030434\&ssTargetNodeld $=373$

2 Hampshire Constabulary. National problem profile: methamphetamine. 2007. www.mhra.gov.uk/home idcplg?IdcService=GET_FILE\&dDocName $=$ con20310 00\&RevisionSelectionMethod=Lates

Proprietary Association of Great Britain. Information on the use ofover-the-counter pseudoephedrine and the link with the making of methylamphetamine. 2007. www.pagb.co.uk/media/downloads/downloads. asp? mode $=$ doc $\&$ id $=289$

4 Fulde G, WodakA. Ice: cool drug or real problem? MedJ Aust 2007;186:334-5.

5 Gray SD, Fatovich DM, McCoubrie DL, Daly FF. Amphetamine-related presentations to an inner-city emergency department: a prospective evaluation. Med J Aust 2007;186:336-9.

6 Flint C. Oral answers. House of Commons Official Report (Hansard) 2007 April 24:col 1052W. Www.publications parliament.uk/pa/cm200607/cmhansrd/ cm070424/text/70424w0011.htm\#column 1052W Advisory Council on the Misuse of Drugs. Methylamphetamine review. 2005. www.drugs.gov, uk/publication-search/acmd/ACMD-meth-reportNovember-2005?view=Binary

8 M. Glossop. Classification of illegal and harmful drugs BMJ 2006:333:272-3. 